\title{
DUAS NOTAS SOBRE O ITINERÁRIO DA PSICANÁLISE
}

\author{
Fabio Herrmann ${ }^{1}$ \\ Sociedade Brasileira de Psicanálise de São Paulo
}

\begin{abstract}
Neste artigo, discutem-se os rumos da implantação da Psicanálise em São Paulo, na Universidade e na Sociedade Brasileira de Psicanálise de São Paulo. Assinalam-se algumas peculiaridades e diferenças dos dois movimentos de propagação, bem como sua inter-relação.
\end{abstract}

Descritores: Psicanálise. História da psicanálise. Universidade.

\begin{abstract}
A s notas que se seguem correspondem a duas aulas de um curso intitulado Da alta teoria à clínica extensa, que vem sendo ministrado simultaneamente na PUC-SP, no Instituto de Psicanálise e na Sociedade Brasileira de Psicanálise de São Paulo, de 2002 a 2004. A aula inaugural foi publicada na Revista Percurso (Herrmann, 2002). No curso examino a circunstância atual da Psicanálise, em especial a crise da clínica padrão, sua ampliação como clínica extensa e a necessidade do desenvolvimento de teorias consentâneas a tal extensão, a cujo conjunto chamo de alta teoria. A primeira Meditação Clínica, de que fazem parte as aulas seguintes, discute a história da psicanálise como resistência à Psicanálise; ou seja, a influência ambígua da terapia de consultório e do movimento psicanalítico sobre a criação e desenvolvimento da ciência da alma humana.
\end{abstract}

Em Freud, a Psicanálise ocupava uma área muito maior que a terapia de consultório; depois, dentro do movimento psicanalítico, não se expandiu, encolheu. A teo-

1 Membro Efetivo e Analista Didata da Sociedade Brasileira de Psicanálise de São Paulo. Professor da PUC-SP. Endereço eletrônico: herrmann@ catnet.com.br 


\section{Fabio Herrmann}

ria psicanalítica, por seu lado, adaptou-se à prática, transformando-se em psicologia individual, e à formação, dividindo-se em sistemas doutrinários escolásticos. (...) Os mesmos acordos políticos que determinaram os centros do poder psicanalítico convencionaram a extensão permissível da clínica e, por tabela, o nível de sua teorização, definindo assim a clínica padrão e a teoria padrão. (...) Hoje, a crise da clínica-padrão força mesmo os grupos mais recalcitrantes a praticarem uma clínica extensa, que se assenta, porém, por equívoco, nas teorias-padrão das escolas, ou, com certa freqüência, numa versão ainda mais simplificada destas; quando, ao contrário, a clínica extensa exige um grau mais elevado de teorização: a "alta teoria" a região que se estende metapsicologia acima até o método psicanalítico. (...) A evolução do pensamento científico, por conseguinte, condensa constantemente teoria em procedimento, o qual, como forma concentrada daquela, entra em combustão espontânea de tempos em tempos, exalando mais teoria. Na Psicanálise, a forma condensada da teoria, o procedimento, é a clínica em toda a sua pujante extensão de direito. Ao destilar-se outra vez em teoria, dela resulta uma "metapsicologia clínica", que, em vez de se enraizar em postulados ontológicos, como impulso, aparelho psíquico ou desenvolvimento primitivo, se funda nos conceitos metodológicos responsáveis pelo ato analítico, como por exe mplo, o de ruptura de campo. Tal "metapsicologia", que apenas nas últimas décadas começa a vislumbrar-se, tende a sublimar os postulados ontológicos, ressignificando-os como epistemologia concreta, ou seja "alta teoria", sem os perder, sem os abandonar. ${ }^{2}$

\section{Psicanálise e Universidade}

A Universidade não depende dos acordos internacionais acerca da clínica padrão ou dos standards da formação, mas sofre seus efeitos gravitacionais, por assim dizer. Imagino, às vezes, se a Universidade não respeita mais o movimento psicanalítico internacional, do que este mesmo se respeita. Por muito tempo, por tempo demasiado, a Psicanálise tentou a Universidade, sem se entregar a ela. Com isso, criourse uma atração de legitimidade. Os trabalhos acadêmicos tendiam a versar sobre a Psicanálise, não a ser Psicanálise. Mesmo quando eram psicanálises, no sentido próprio do termo, restava certo escrúpulo dos autores em o declarar, como se temessem ser

2 Material inédito de aulas proferidas pelo autor no curso Da alta teoria à clínica extensa, que vem sendo ministrado, simultaneamente, na PUC-SP, no Instituto de Psicanálise e na Sociedade Brasileira de Psicanálise de São Paulo, de 2002 a 2004. 
acusados de charlatanismo. Não sou psicanalista, não fiz formação, não me analise - eram frases que se ouvia a todo momento. Excelentes psicanálises da literatura, por exemplo, acompanhavam-se sempre dessa mea culpa.

A chegada da psicanálise lacaniana à Universidade brasileira modificaria um pouco a situação. Em parte, pela alegação de que o analista se autoriza por si, em parte, pelo fato de os grupos lacanianos já chegarem multiplicados e divididos, em parte, porque se rompera o monopólio e onde há dois, há mil. Ao montarem base na Universidade, como estratégia natural de inserção, os analistas lacanianos, ao contrário dos da International Psychoanalytical Association, podiam dedicar mais tempo e mais empenho à atividade acadêmica. Sua vitória foi arrasadora e imediata, na maioria dos casos.

Depois, a situação viria a complicar-se, pois, aos poucos, foi-se formando um estilo universitário, fortemente influenciado pelo discurso lacaniano, porém, fora de seus quadros. Esse estilo à la française, mais culto que o da IPA, mais freudiano, mais chegado à literatura que ao relato de sessão, por vezes tão metafórico e barroco que nele não se consegue distinguir assunto de retórica, outras vezes, bastante rigoroso, é hoje dominante. Mesmo os trabalhos de origem diversa, quando apresentados à Universidade, mostram regularmente sinais de sua influência.

Do ponto de vista temático, o estilo universitário apresenta uma curiosa peculiaridade. É difícil julgar se ela se deve à influência dos lacanianos, pois historicamente os antecede. Talvez, constitua um caso de influência circular: a psicanálise francesa foi influenciada pelo estilo universitário e o propagou em seguida, inclusive para a própria Universidade. Refiro-me à postura filosófica, que toma a obra de Freud pela Psicanálise, pars pro toto, e trata a obra freudiana como um sistema conceitual, cujas bases dínicas supõe constantemente, mas não se anima a investigar. Raramente questiona se a experiência clínica pode ou não provar a existência de tal ou qual fenômeno ou sustentar certo conceito. Lendo teses e demais trabalhos acadêmicos, tem-se a impressão de que ainda espiam a Psicanálise de fora, não mais por interdição, mas por hábito. Em princípio, esta peculiaridade não é um defeito. A Psicanálise necessita também de seus scholars. A chegada à Uni- 
versidade de analistas vindos da filosofia, literatura, lingüística, sociologia e de psicólogos com formação filosófica contribuiu decisivamente para tornála menos ingênua e autocentrada. O problema só apareceu porque o número de teses aumentou exponencialmente, ao longo das duas últimas décadas. Precisamos de scholars, mas não de tantos, e desconfio que começa a faltar Freud para tanta tese. Alguns temas repetem-se à saciedade, outros parecem microscopia da poeira estelar, esmiuçando conceitos que mal existem, ou discutindo tênues parentescos conceituais, decididamente por capricho.

Acredito que se possa rastrear a causa desse fenômeno, reconhecendo de início que a história acima esboçada contribui para ele. A outra vertente causal pode ser descrita como análise de fotogramas. Os conceitos psicanalíticos, os de Freud assim como os de todos os demais autores, só adquirem pleno sentido quando em movimento, como os fotogramas que compõem um filme. Fazem sentido no curso de uma psicanálise, seja esta clínica, padrão ou extensa, literária, cultural etc. - por simplicidade, prefiro reunir todas essas variantes sob o título de clínica extensa, já que a aplicação do método interpretativo sempre tem uma dimensão de cura, clínica, mesmo quando não diz respeito a doença alguma. Digamos que o método psicanalítico é tanto a câmera que filmou, quanto o projetor que exibe. No meio, há um trabalho teórico, equivalente ao do diretor que seleciona as cenas, que corta o copião e o monta. Esta é uma operação propriamente teórica, porque redunda num efeito concreto. Já a análise de um conjunto de fotogramas imóveis dificilmente pode formar uma Gestalt significativa. Discutir os conceitos da Psicanálise, em estado teórico, o oposto a estado nascente ou estado clínico, pode levar rigorosamente a qualquer conclusão, pois estes não se derivam um do outro, nem se relacionam diretamente entre si. Só em movimento, como interpretantes de uma psicanálise, mesmo que de uma psicanálise ficcional, hipotética ou quase conjectural, entram de fato em relação às diversas redes conceituais da Psicanálise. A Psicanálise é o método interpretativo em ação, não uma teoria.

O espaço heurístico que se abre entre a clínica padrão e a discussão teórica exerce um forte poder de atração. É de se esperar que o emprego do método psicanalítico de investigação na Universidade (como propõe a Teo- 
ria dos Campos) ajude a equilibrar a tendência ao comentário sobre as teorias, que constitui ao mesmo tempo o mérito e o problema de nossa produção acadêmica

\section{IPA, Sociedade}

Aqui, ao contrário, o problema foi a organização da Psicanálise segundo os moldes de uma corporação medieval. A transmissão do ofício, de mestre a aprendiz, deixaria marcas internas: a emolduração dos candidatos e o circuito de realização teórica, ${ }^{3}$ garantidos ambos pela convergência entre análise didática, supervisão e ensino teórico que, cumpridos dentro da mesma corrente, dão realidade psíquica à teoria. Como nas corporações de ofício, temia-se mais o desvirtuamento que a paralisia, incentivava-se a fidelidade à forma bem acima da invenção, sendo possível, por intermédio da relação de aprendizado, perpetuar os padrões do trabalho artesanal (clinical standards), contornando o óbice de explicar sua evidente arbitrariedade.

Certas marcas externas à formação decorreriam igualmente do espírito de corporação. Quando foi preciso incluir novo pólo de poder, o norteamericano, a IPA assumiu um aspecto comparável talvez ao da Liga Anseática, tendo Londres como centro, no lugar da Lübeck medieval, e cidades coligadas agora no Novo Mundo. O centro teórico era preservado, às custas, porém, de conceder uma relativa independência prática ao parceiro, ou melhor, de fazer vistas grossas ao que se passava no outro lado do oceano, uma vez que a delegação americana, segundo se conta, fez ver a Ernest Jones, sem rodeios, que ou os deixava em paz para fazer do seu jeito, ou paravam de pagar. A Psicanálise apenas se internacionalizaria, portanto, no sentido rigoroso de expansão colonizadora, quando do descobrimento psicanalítico da América Latina e, muito depois, do assim chamado resto do mundo, Europa Oriental, Ásia, Austrália. Então, aproximourse um tanto o modelo ao

3 Problemas que analiso em meu artigo: “Análise didática em tempos de penúria teórica” (Herrmann, 1998). 
das Companhias das Índias, empreendimento mais ambicioso de exploração colonial do além-mar. Somente agora, surgiriam os residentes - nos EUA foi-lhes conveniente sempre que possível naturalizar-se, por força da Segunda Guerra. Em seguida, aos residentes estrangeiros, vieram juntar-se os representantes locais na geração seguinte, formados nas matrizes européias, ou que para lá viajavam a fim de receber treinamento complementar e serem investidos na função. Chegamos, com esta última modernização, quase ao nível das companhias bananeiras e, em geral, ao das empresas de desenvolvimento e colonização; não sendo possível atingir este estágio, todavia, por falta de capital - a IPA sempre contou com recursos extremamente modestos - e pela prevalência, mesmo nos centros metropolitanos mais avançados, do sistema de guildas na organização interna, cujo sistema de auxílio mútuo excluía uma autêntica competição. Ademais, como extrativismo e mão de obra barata não chegam a fazer sentido nesse processo colonizador institucionalmente pouco rentável, sobressaiu largamente a dimensão religiosa, secundária nos empreendimentos congêneres; ou seja, as missões, mais empenhadas em conseguir vocações e áreas de prestígio para cada escola do que em obter lucro direto. Testemunho do caráter sobretudo religioso da propagação da psicanálise européia às regiões dependentes é dado pela instituição de uma terceira figura, responsável pelo controle dos próprios residentes - quando se deixavam seduzir pelas facilidades da vida na colônia, cometendo desmandos inescusáveis - e daqueles representantes que, às vezes, passavam a abusar da investidura em vantagem própria: criaram-se os visitadores. Os relatórios das comissões de visitadores (visiting committees) e os autos dos processos instaurados a partir deles ofereceriam peças altamente instrutivas para a reconstituição da história missionária da IPA, não fora seu caráter sigiloso, que sempre constituiu praxe em semelhantes procedimentos.

O desafio francês à hegemonia inglesa, que parecia inicialmente ameaçar a preponderância da metrópole psicana lítica, deu novo alento à disputa de mercado no último quarto do século XX e, por consequiência, acirrou a polêmica teórica. Se cada grupo mantinha internamente o sistema corporativo, a luta pela supremacia na difusão criou um espaço um pouco mais pare- 
cido ao do capitalismo clássico. Neste, a questão de qualidade já se manifestava, e deveria manter-se viva e ativa, por interesse recíproco. Qual a melhor psicanálise? A discussão entre os partidários de cada etnia, com suas diferenças e matizes na região de origem, era conduzida pelos residentes, logo, pelos representantes e, nalguns casos, por intérpretes locais mais ou menos independentes, embora sempre dirigidos de alguma maneira pela matriz correspondente. O fundamental, ao que parece, era manter acesa a disputa, não apenas para impedir as veleidades de criação autônoma local, fenômeno raro, como principalmente a interferência de outros missionários comerciais. Convém não esquecer a ameaça constante de expansão da psicanálise norteamericana, que se fez sentir em diversos países, chegando a dominar o México, por exemplo; até quase o fim da década de 80, era costume que cada Presidente da Associação Norte Americana realizasse um giro de conferências pela América Latina, só sendo abandonada tal prática quando os latinoamericanos sugeriram a conveniência da reciprocidade de tais visitas.

Conquanto decorrência da necessidade de manutenção da disputa entre o inglês e o francês, como parte de um processo monopolista a dois, se tal abuso semântico é permitido - o termo oligopólio seria impróprio -, a presença de um estilo freudo-lacaniano só muito tardiamente se faria sentir na Sociedade de São Paulo, por razões locais sobejamente conhecidas, bem depois de se ter implantado em Buenos Aires e Caracas, por exemplo, e mesmo depois do Rio de Janeiro. Surgiu de início como um simples discurso ideológico. Parecia mais moderno e definitivamente mais internacional praticar uma psicanálise inglesa com sotaque francês, incorporando o discurso metafórico, popularizado por Lacan, ao setting e à técnica kleinianos.

Em pouco tempo, não obstante, o que era uma concessão ao galicismo da fala e, mais raramente, da escrita, abriria o espaço para uma autêntica, embora incipiente, discussão de princípios teóricos e de orientação da clínica de consultório. Valorizou-se o estudo de Freud, o que constituiu um avanço objetivo, mesmo que lutando contra intensa oposição, representada principalmente pela leitura de superfície de sua obra. Outro aspecto positivo, este devido mais ao discurso ideológico de modernização, foi a incorporação dos chamados autores contemporâneos, ingleses, franceses - mas até norte- 
americanos, italianos etc. -, mesmo que regularmente descartados após um uso intenso e entusiástico.

Em anos recentes, começamos a presenciar uma verdadeira disputa, ainda que desproporcional, entre ingleses e franceses. Sem prejuízo de cumprir a função essencial de manutenção do status quo, estabelecido a partir dos anos 60, a reedição em solo paulista dessa querela poderá trazer novo alento a uma vida societária que parecia condenada ao esmorecimento terminal. Nota-se, entre os candidatos principalmente, certa exigência no que respeita ao ensino da obra freudiana, exigência a que, de alguma maneira, a Instituição terá de responder. Que a nascente disputa reedite muito do que se passou nos centros de exportação, durante as décadas 60 e 70, só de leve pode empanar o brilho de modernidade de que se reveste o ideal de eterno retorno a Freud - ademais, absolutamente necessário entre nós. Mas não será, porventura, senão um dos inevitáveis desdobramentos de nosso crônico torcicolo cultural, no dizer de Schwarz (2001), em "As idéias fora de lugar", presente em acirrados debates, deslocados no espaço e no tempo, de onde regularmente os incompatíveis saem de mãos dadas.

É evidente que a questão mais contemporânea, e na realidade dominante em todo o mundo psicanalítico, no desenvolvido ou no dependente, reside no naufrágio da clínica padrão. Mesmo a disputa anglo-francesa pela supremacia refere-se em essência à psicanálise de consultório conduzida segundo os standards técnicos e, mais especificamente, ao recrutamento e formação de analistas nela especializados. Vem daí certo desânimo que hoje se generaliza, pois, se é possível manter por algum tempo os escalões mais altos da psicanálise à custa da formação e do clientelismo estrangeiro, uma seca prolongada pode pôr a nave a pique - contradição tão-somente metafórica. Esta problemática tem sido maquiada entre nós, porém, e só será aqui absorvida quando a pressão econômica obrigar a admiti-la - então, espera-se, já haverá algum respeitável modelo europeu ou quem sabe norte-americano a importar, perpetuando o atraso crônico que nos identifica, como uma carteira de identidade. Tradição é o que tem quem acredita que tem tradição, mas somos tão apegados ao complexo de vira-lata, como batizou Nelson 
Rodrigues nossa mais autêntica ideologia, que nada teremos a fazer com a consciência atual do problema e do caminho para sua solução.

De momento, de nada vale e só apressa a crise a tentativa de juntar biblicamente vinho novo ao odre velho. A conclamação a integrar-se na comunidade, conduzida com recursos escolásticos, pode contribuir para maior descrédito dos psicanalistas, caso continue a predominar nesse setor o caráter intrinsecamente missionário, que supõe anunciar a boa nova aos gentios. Quanto à conquista de espaço na IPA, se não serve a sustentar ou expandir idéia alguma nascida em nosso meio, tende a consagrar o princípio neodarwinista de sobrevivência do mais dócil. Não há maneira alguma de entrar na disputa internacional atualmente. "O subdesenvolvido faz um imperialismo às avessas. Vai ao estrangeiro e, em vez de conquistá-lo, ele se entrega e se declara colônia" (Rodrigues, 2001, p. 123). Por outro lado, o desenvolvimento de uma clínica extensa dar-se-á, quase com certeza, fora das instituições oficiais, enquanto, por sua parte, a alta teoria que necessariamente lhe corresponde deverá ser desenvolvida, também parece provável, em âmbitos muito restritos e sem debate internacional. Este é um quadro de difícil reversão, salvo alguma intervenção providencial do acaso.

Herrmann, F. (2003). Two notes on the itinerary of Psychoanalysis. Psicologia USP, 14(3), 79-88.

\begin{abstract}
In the present article, the routes of implantation of Psychoanalysis in São Paulo, at the University and at the Psychoanalytical Society (SBPSP) are discussed. Some peculiarities and differences of both propagation processes, as well as their interrelation are outlined.
\end{abstract}

Index terms: Psychoanalysis. History of psychoanalysis. University. 


\section{Fabio Herrmann}

Herrmann, F. (2003). Deux Notes Sur L'itinéraire De La Psychanalyse. Psicologia USP, 14(3), 79-88.

Résumé: Cet article discute sur les chemins de l'implantation de la psychanalyse à São Paulo, dans l'université et dans la société brésilienne de psychanalyse de São Paulo. On signale quelques particularités et différences dans les mouvements de propagation, et leurs interrelations.

Mots-clés: Psychanalyse. Histoire de la Psychanalyse. Université.

\section{Referências}

Herrmann, F. (1998). Análise didática em tempos de penúria teórica. Revista Brasileira de Psicanálise, 32(4), 697-709.

Herrmann, F. (2002). Da clínica extensa à alta teoria: A história da psicanálise como resistência à psicanálise. Percurso: Revista de Psicanálise, 15(29), 15-20.

Rodrigues, N. (2001). Coisas e relinchos triunfais. In N. Rodrigues, A pátria em chuteiras. São Paulo: Companhia das Letras.

Schwarz, R. (2001). As idéias fora de lugar. In R. Schwarz, Ao vencedor as batatas (5a ed., pp. 9-31). São Paulo: Ed. 34.

Recebido em 28.02.2003

Aceito em 13.03.2003 